\title{
CARACTERÍSTICAS QUALITATIVAS E MICROBIOLÓGICAS DA PALETA DE CORDEIROS
}

Fabiola Cristine de Almeida Rego ${ }^{1}$, Caio Henrique Favaro ${ }^{1}$, Lais Belan ${ }^{1}$, Camila Constantino ${ }^{2}$, Joice Sifuentes dos Santos ${ }^{1}$, Luiz Cesar da Silva ${ }^{1}$, Luiz Fernando Coelho Cunha ${ }^{1}$, Elsa Helena Walter de Santana ${ }^{1}$,Marilice Zundt ${ }^{3}$

${ }^{1}$ Universidade Norte do Paraná - UNOPAR, Programa de Mestrado em Saúde e Produção de Ruminantes e Curso Medicina Veterinária. ${ }^{2}$ Universidade Estadual de Londrina - UEL, Londrina - PR. ${ }^{3}$ Universidade do Oeste Paulista UNOESTE, Presidente Prudente - SP.E-mail: fabiolaregogrecco@gmail.com.

\section{RESUMO}

Objetivou-se com este trabalho avaliar a qualidade da carne de cordeiro embalada a vácuo (nacional e importada) comercializada no município de Londrina - PR. As amostras de paletas de cordeiro foram avaliadas quanto a sua composição, cor, pH, perda de água por pressão (PAP) e qualidade microbiológica. A composição foi $70,6 \%$ de umidade, $21,9 \%$ de proteínas, $6,6 \%$ de extrato etéreo e $0,9 \%$ de cinzas. Os valores de $\mathrm{pH}$ variaram de 5,89 a 6,18, com pH médio de 6,1. Os parâmetros de cor L* e b* foram 40,04 e 15,06, respectivamente; e o parâmetro a* apresentou diferença entre as amostras nacional e importada, sendo 22,44 e 18,83 , respectivamente. A PAP média foi de $65,7 \%$. As características qualitativas do corte comercial de cordeiro nacional e importado estão dentro dos padrões da literatura. As características microbiológicas da carne ovina analisadas apresentaram-se aquém às recomendações da Legislação Brasileira em alguns quesitos, como presença de Salmonella spp. na carne nacional.

Palavras-chave: carne ovina, paleta, composição, cor, Legislação.

\section{QUALITATIVE AND MICROBIOLOGICAL CHARACTERISTICS OF LAMBS PALETTE}

\begin{abstract}
The objective of this study was to evaluate the quality of lamb meat vacuum packaged (national and imported origin) commercialized in Londrina - PR. Lamb palette samples were evaluated for composition, color parameters, hydrogen potential $(\mathrm{pH})$, loss of water under pressure (LWP) and microbiological quality. The composition of the samples was $70.6 \%$ moisture, $21.9 \%$ protein, $6.6 \%$ fat and $0.9 \%$ ash. The $\mathrm{pH}$ values ranged from 5.89 to 6.18 , with an average $\mathrm{pH}$ of 6.1 . The color parameters $L^{*}$ and $b *$ were 40.04 and 15.06, respectively; and the parameter a * was different between the national and imported samples, 22.44 and 18.83, respectively. The LWP was $65.7 \%$. Qualitative characteristics of the national and imported commercial cut of lamb meat from are within normal standards of literature. The microbiological characteristics of lamb meat are out the recommendations of the Brazilian legislation on some issues, such as the presence of Salmonella spp. in the national meat.
\end{abstract}

Keywords: ovine meat, palette, composition, color, Legislation.

\section{INTRODUÇÃO}

A qualidade da carne é influenciada por diversos fatores, que vão desde o método de criação dos animais até a embalagem do produto final, envolvendo todas as etapas da cadeia 
produtiva. Sendo assim, são de importância os parâmetros nutricionais (teores de proteína bruta e gordura, perfil de ácidos graxos, teor de minerais e vitaminas); os parâmetros tecnológicos (pH e perda de água por pressão); os parâmetros sensoriais (cor, textura, suculência, sabor, odor, maciez); e os parâmetros sanitários (presença de Salmonela spp., Escherichia coli, Staphylococcus spp., fungos e leveduras).

Segundo Prändal et al. (1994), algumas destas características, como a cor, a perda de água por pressão e a maciez, podem sofrer influência do $\mathrm{pH}$, pois além de alterar as características organolépticas da carne, é um dos fatores determinantes na velocidade de instalação do rigor mortis. Sabe-se que a maciez está intimamente relacionada à perda de água por pressão, ao pH, ao estado de engorduramento e às características do tecido conjuntivo e da fibra muscular (ZEOLA; SILVA SOBRINHO, 2001).

Os varejistas consideram a cor da carne fator de importância primária na aceitação pelos consumidores (TRUSCOTT et al., 1984), que preferem a cor vermelho-vivo (oximioglobina) da carne fresca, preterindo a cor marrom (metamioglobina). A cor da carne pode ser medida pelo método objetivo, utilizando-se colorímetro, que determina os componentes de cor $\mathrm{L}^{*}$ (luminosidade), a* (teor de vermelho) e b* (teor de amarelo). Carnes com menor L* e maior a* apresentam cores mais vermelhas (SIMÕES; RICARDO, 2000).

A cor é a característica mais importante para o consumidor no momento da compra, e reflete o estado químico e o teor de mioglobina no músculo. O consumidor assumiu que a cor vermelho brilhante se relaciona a animais jovens com carne mais macia. No entanto, a cor da carne é também uma questão cultural, já que em países como a Espanha, o consumidor prefere a carne de coloração mais clara, enquanto outros países da Europa dão preferência à carne de coloração um pouco mais escura (OSÓRIO et al., 1998).

A avaliação da presença de coliformes totais na carne é muito importante para a saúde pública, uma vez que esse grupo inclui três gêneros, Escherichia, Enterobacter e Klebsiella, sendo as cepas de Enterobacter e Klebsiella de origem não fecal. Já a Escherichia coli é de origem fecal, sendo seu habitat o trato gastrintestinal; e quando presente nos alimentos indica a contaminação fecal, em alimentos processados (SILVA,1997).

A oferta de alimentos de boa qualidade exige uma série de medidas de controle em todas as etapas da cadeia de produção. Da mesma forma, produtores de alimentos e o mercado varejista devem atender à demanda dos consumidores por qualidade e segurança alimentar. $\mathrm{O}$ objetivo do presente trabalho é avaliar a qualidade de amostras de paleta ovina, de origem nacional e importada, comercializadas em Londrina - PR. 


\section{MATERIAL E MÉTODOS}

Foram avaliadas oito amostras de carne de cordeiros, quatro nacionais e quatro importadas, sendo cortes de paleta congelados embalados a vácuo. As amostras foram coletadas em diferentes estabelecimentos comerciais na região Londrina - PR durante o mês de fevereiro de 2014. As peças de carne foram transportadas em caixas de isopor com gelo e mantidas resfriadas até a avaliação.

As medidas de cor, $\mathrm{pH}$ e perda de água por pressão (PAP) foram realizadas no mesmo dia em que a carne saiu da prateleira do estabelecimento, utilizando o músculo Biceps brachii. A cor foi analisada utilizando o aparelho colorímetro portátil (Minolta) para avaliação dos componentes $L^{*}$ (luminosidade), $a^{*}$ (componente vermelho-verde) e $b^{*}$ (componente amarelo-azul) que foram expressos no sistema de cor CIELAB (HOUBEN et al., 2000). As amostras foram analisadas em triplicata. $\mathrm{O}$ pH da carne foi medido na mesma porção na qual foi realizada a leitura da cor, utilizando-se o peagâmetro portátil com eletrodo de inserção (Hanna). A PAP foi avaliada pelo método de pressão em papel filtro, colocando uma porção conhecida de carne entre duas folhas de papel filtro, exercendo uma pressão com peso de $10 \mathrm{~kg}$ durante cinco minutos (BARBUT, 1996).

Ainda no mesmo dia foram colhidas ao acaso três porções de cada paleta de cordeiro para as análises microbiológicas, verificando a presença de Staphylococcus, coliformes totais, Escherichia coli, Salmonella spp. e bolores e leveduras, segundo metodologias descrita por Siqueira (1995).

Para determinar a composição centesimal da carne foi utilizado o músculo supra-espinal. As amostras foram moídas em moedor de carne e secas em estufa de circulação de ar forçado a

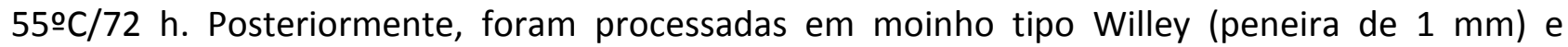
determinados os teores de umidade, proteína bruta, extrato etéreo e cinzas (AOAC, 1990). As amostras foram analisadas em duplicata.

Os dados de composição, parâmetros de cor, pH e perda de água por pressão foram analisados através do teste não paramétrico de Mann-Whitney, com nível de significância de 5\%, utilizando o programa Statistica 7.0.

\section{RESULTADOS}

Na Tabela 1 encontram-se a composição, os valores de coloração $\left(L^{*}, a^{*}, b^{*}\right), p H$ e perda de água por pressão. 
Tabela 1. Composição química, parâmetros de cor, pH e perda de água por pressão de amostras de paleta ovina comercializadas em Londrina - PR.

\begin{tabular}{lcc}
\hline Parâmetro & Carne nacional & Carne importada \\
\hline Umidade (\%) & $70,12^{\mathrm{a}} \pm 1,66$ & $71,05^{\mathrm{a}} \pm 2,45$ \\
Proteínas (\%) & $21,93^{\mathrm{a}} \pm 1,07$ & $21,95^{\mathrm{a}} \pm 0,74$ \\
Extrato etéreo (\%) & $6,92^{\mathrm{a}} \pm 1,95$ & $6,18^{\mathrm{a}} \pm 2,58$ \\
Cinzas (\%) & $0,97^{\mathrm{a}} \pm 0,07$ & $0,96^{\mathrm{a}} \pm 0,02$ \\
Luminosidade & $40,59^{\mathrm{a}} \pm 4,12$ & $39,49^{\mathrm{a}} \pm 2,60$ \\
A $^{*}$ & $22,44^{\mathrm{a}} \pm 3,08$ & $18,83^{\mathrm{b}} \pm 1,26$ \\
B $^{*}$ & $15,87^{\mathrm{a}} \pm 1,82$ & $14,26^{\mathrm{a}} \pm 0,90$ \\
pH & $6,03^{\mathrm{a}} \pm 0,10$ & $6,16^{\mathrm{a}} \pm 0,13$ \\
Perda de água por pressão & $64,49^{\mathrm{a}} \pm 2,99$ & $66,87^{\mathrm{a}} \pm 1,19$ \\
\hline
\end{tabular}

Resultados são apresentados como Média \pm Desvio Padrão.

Letras sobrescritas diferentes nas linhas indicam diferença estatística pelo teste de Mann-Whitney $(p<0,05)$.

Não houve diferença significativa $(p>0,05)$ para a composição da carne ovina nacional e importada (Tabela 1).

Observou-se diferença significativa no parâmetro de cor a* entre as amostras de procedência nacional e importada $(p<0,05)$. Os valores de $\mathrm{pH}$ (Tabela 1$)$ não apresentaram diferença estatística $(p>0,05)$ entre as carnes nacional e importada e podem ser considerados elevados.

A perda de água por pressão (Tabela 1) foi semelhante entre as amostras de carne ovina nacional e importada ( $p>0,05)$, com valor médio de $65,7 \%$.

A Tabela 2 apresenta os dados de avaliação microbiológica das amostras.

Tabela 2. Análise microbiológica de amostras de paleta ovina comercializadas em Londrina - PR.

\begin{tabular}{l|c|c|c|c}
\hline \multirow{2}{*}{ Microrganismo } & \multicolumn{2}{|l|}{ Carne nacional } & \multicolumn{2}{l}{ Carne importada } \\
\cline { 2 - 5 } & Frequência & Contagem & Frequência & Contagem \\
\hline Salmonella spp. & $1 / 4$ & & $0 / 4$ & \\
\hline $\begin{array}{l}\text { Staphylococcus } \\
\text { coagulase positiva }\end{array}$ & $3 / 4$ & $2,21 \times 10^{4}$ & $4 / 4$ & $2,02 \times 10^{3}$ \\
\hline Coliformes totais & $4 / 4$ & $2,1 \times 10^{2} \mathrm{a}>2,4 \times 10^{3}$ & $4 / 4$ & $3 \mathrm{a}>2,4 \times 10^{3}$ \\
\hline Escherichia coli & $4 / 4$ & $4,15 \times 10^{2}$ & $4 / 4$ & $3 \mathrm{a}>2,4 \times 10^{3}$ \\
\hline Bolores e leveduras & $4 / 4$ & $2,0 \times 10^{3} \mathrm{a}>10^{5}$ & $4 / 4$ & $1,2 \times 10^{4} \mathrm{a}>10^{5}$ \\
\hline
\end{tabular}

Contagens de Staphylococcus coagulase positiva e bolores e leveduras em UFC/g. contagens de coliformes totais e Escherichia coli em NMP.

Entre as oito amostras analisadas, uma foi positiva para presença de Salmonella spp (Tabela 2). 
Apenas uma amostra não apresentava Staphylococcus coagulase positiva (Tabela 2).

A presença de coliformes totais foi observada em todas as amostras analisadas, sendo que em quatro amostras a contagem foi superior a $2,4 \times 10^{3}$ NMP.

Todas as amostras analisadas apresentaram contaminação por bolores e leveduras (Tabela 2).

\section{DISCUSSÃO}

A composição destas amostras foi semelhante aquela encontrada por Pinheiro et al. (2009), que observaram valor de $74 \%$ de umidade, $18,8 \%$ de proteínas, 5,4\% de extrato etéreo e $1,1 \%$ de cinzas. No entanto, Freire et al. (2010) encontraram valores superiores de cinzas $(1,4 \%)$ e inferiores de extrato etéreo $(3,1 \%)$. É importante ressaltar que as amostras adquiridas no presente trabalho não tem identificação de raça, e algumas das diferenças observadas são devidas a este fator, bem como ao manejo e a nutrição dos animais.

O parâmetro de cor $a^{*}$ é referente à intensidade da cor vermelha, tendo apresentado menor intensidade nas amostras de carne importada. No trabalho de Fernandes et al. (2012), ao analisarem carne ovina embalada a vácuo estocada sob refrigeração, os autores observaram valores inferiores ao presente estudo ao fim de 28 dias de refrigeração $\left(L^{*}=36,5 ; a^{*}=6,9 ; b^{*}=\right.$ 10,5). Bressan et al. (2001) também observaram valores inferiores na composição da cor (L* de 32,46 a 42,$29 ; a^{*}$ de 10,39 a 13,$89 ; b^{*}$ de 6,73 a 8,15$)$. No entanto, assim como no presente estudo, Perez et al. (1997) encontraram valores de cor superiores $\left(L^{*}=32,58-32,78 ; a^{*}=15,58\right.$ 15,$\left.97 ; b^{*}=3,38-3,55\right)$, revelando que as amostras foram mais escuras. As discrepâncias com a literatura nos padrões de coloração ocorreram principalmente nos valores de b*. Isso pode ser explicado pelos diferentes tipos de sistemas de criação e terminação aos quais os animais foram submetidos, uma vez que não são conhecidas as procedências e os respectivos sistemas de criação das carnes avaliadas. Além disso, segundo Bressan et al. (2001), os valores de L*, a* e b* tendem a modificar com o aumento do peso de abate, devido à maior musculosidade do animal.

$\mathrm{O} \mathrm{pH}$ inicial da carne facilita o crescimento de microrganismos, $\mathrm{pH}$ mais baixos $(5,4$ a 5,6$)$ facilitam o crescimento de bactérias láticas, enquanto $\mathrm{pH}$ próximo de 5,8 a 6,0 facilitam o crescimento de Pseudomonas spp. (MANO et al., 2002).

A perda de água por pressão apresentou valores um pouco inferiores aos encontrados na literatura, o que possivelmente seja em virtude da carne ser congelada e apresentar maior quantidade de exsudato. Outros autores encontraram PAP superior ao presente trabalho, como Françoso (2014) e Baise (2014), que observaram valores de 75,0 e 74,7\% respectivamente. 
A Legislação Brasileira preconiza ausência de Salmonella spp em 25 g de amostra (BRASIL, 2001). Em trabalho realizado no Recife, Fernandes et al. (2009) observaram contaminação com Salmonella spp em 8/26 amostras de carne de cordeiro comercializadas em mercados públicos.

S. aureus é responsável por diversos surtos de toxinfeccões alimentares, muitas vezes levando a quadro graves com necessidades de internações hospitalares, principalmente decorrente do efeito da sua enterotoxina (GERMANO; GERMANO, 2008). A Legislação Brasileira permite um limite máximo de Staphylococcus coagulase positiva em carnes resfriadas ou congeladas de $3 \times 10^{3} \mathrm{UFC} / \mathrm{g}$ (BRASIL, 2001). Uma amostra de carne nacional apresentou contaminação superior ao máximo permitido, sendo considerada imprópria para o consumo. Fernandes et al. (2009) observaram 16/26 amostras impróprias para o consumo quanto a presença de S. aureus; com valores nos limites entre $6,7 \times 10^{3}$ e $2,03 \times 10^{6} \mathrm{UFC} / \mathrm{g}$.

O valor máximo permitido para contaminação por coliformes totais é de $10^{4} \mathrm{NMP}$ (BRASIL, 2001). Com relação à presença de Escherichia coli, todas as amostras apresentaram contaminação. Fernandes et al. (2009) observaram contaminação por coliformes totais e coliformes termotolerantes em níveis acima dos permitidos em todas as 26 amostras analisadas.

A presença de coliformes totais e Escherichia coli em alimentos processados é uma indicação de que as práticas de higiene e sanitização estão aquém dos padrões requeridos para o processamento de alimentos (SILVA, 1997).

A contaminação de alimentos por bolores e leveduras pode ser atribuída a utilização de utensílios de madeira, que absorvem umidade e impregnam-se de matéria orgânica, tornando-se ideais para a proliferação destes microrganismos. Os problemas causados pelo desenvolvimento de fungos nos alimentos e suas matérias-primas são motivos de preocupação para a indústria de alimentos. A preocupação ocorre não apenas pelo fato de reduzir consideravelmente o valor nutritivo do produto contaminado, mas também pela possível presença de micotoxinas.

\section{CONCLUSÕES}

As características qualitativas do corte comercial de cordeiro proveniente da carne nacional e da importada estão dentro dos padrões normais da literatura. As características microbiológicas apresentaram-se aquém às recomendações da Legislação Brasileira em alguns quesitos, como presença de Salmonella spp. na carne nacional, e o número elevado de Staphylococus coagulase positiva nas carnes nacional e importada. 


\section{REFERÊNCIAS}

ASSOCIATION OF OFFICIAL ANALYTICAL CHEMISTS. Official methods of analysis. 15ed. Arlington, 1990. V.1, 1117p.

BAISE, J. Viabilidade nutricional e econômica da substituição do farelo de milho por bagaço de laranja na dieta de terminação de cordeiros. 2014. 60 f. Dissertação (Mestrado em Saúde e Produção de Ruminantes) - Universidade Norte do Paraná, Londrina.

BARBUT, S. Estimates and detection of the PSE problem in young turkey breast meat. Canadian Journal of Animal Science, Sherbrooke, V. 76, N. 3, P. 455-457, 1996. http://pubs.aic.ca/doi/pdf/10.4141/cjas96-066.

BRASIL. Ministério da Saúde. Agência Nacional de Vigilância Sanitária Resolução-RDC no 12 de 02 de janeiro de 2001. Regulamento técnico sobre padrões microbiológicos para alimentos.

BRESSAN, M.C.; PRADO, O.V.; PÉREZ, J.R.O.; LEMOS, A.L.S.C., BONAGURIO, S. Efeito do peso ao abate de cordeiros Santa Inês e Bergamácia sobre as características físico-químicas da carne. Ciência e Tecnologia de Alimentos, v. 21, n. 3, p. 293-303, 2001. http://dx.doi.org/10.1590/S0101$\underline{20612001000300008 .}$.

FERNANDES, E.F.T.S.; PAULO, A.A.; FERNANDES, M.F.T.S.; MOURA, A.P.B.L.; MOTA, R.A. Qualidade microbiológica da carne de ovinos (Ovis aries) comercializadas nos mercados públicos do Recife-PE. Medicina Veterinária. v.3, n.4, p.7-12, 2009.

FERNANDES, R.P.; FREIRE, M.T.A.; GUERRA, C.C.; CARRER, C.C.; BALIEIRO, J.C.C.; TRINDADE, M.A. Estabilidade físico-química, microbiológica e sensorial de carne ovina embalada a vácuo estocada sob refrigeração. Ciência Rural, v.42, n.4, p.724-729, 2012. http://dx.doi.org/10.1590/S0103$\underline{84782012000400025}$.

FRANÇOSO, M. C. Glicerina bruta em substituição ao milho na dieta de cordeiros confinados. 2014. 70 f. Dissertação (Mestrado em Saúde e Produção de Ruminantes) - Universidade Norte do Paraná, Londrina.

FREIRE, M.T.A.; NAKAO, M.Y.; GUERRA, C.C.; CARRER, C.C.; SOUZA, S.C.; TRINDADE, M.A. Determinação de parâmetros físico-químicos e de aceitação sensorial da carne de cordeiros proveniente de diferentes tipos raciais. Alimentos e Nutrição, v.21, n3, p.481-486, 2010.

GERMANO, P.M.L.; GERMANO, M.I.S. Higiene e vigilância sanitária de alimentos. São Paulo: Manole, 2008.

HOUBEN, J.H.; DIJK, A.; EIKELENBOOM, G. et al. Effect of dietary vitamin E supplementation, fat level and packaging on colour stability and lipid oxidation in minced beef. Meat Science, v.55, p.331-336, 2000.

MANO, S.B.; PEREIRA, J.A.O.; FERNANDO, G.D.G. Aumento da vida útil e microbiologia da carne suína embalada em atmosfera modificada. Ciência e Tecnologia de Alimentos, v.22, n.1, p.1-10, 2002. http://dx.doi.org/10.1590/S0101-20612002000100002. 
OSÓRIO, J.C.S.; SAÑUDO, C.; OSÓRIO, M.T.M. et al. Produção de carne ovina, alternativa para o Rio Grande do Sul. Pelotas: Universidade Federal de Pelotas, 1998.

PEREZ, J.R.O; BONAGURIO, S; BRESSAN, M.C; PRADO, O.V. Efeito dos Dejetos de Suíno na Qualidade da Carne de Ovino. In: Reunião Da Sociedade Brasileira De Zootecnia, 34, Juiz de Fora, 1997. Anais... Juiz de Fora: SBZ, 1997, v.1, p. 391.

PINHEIRO, R.S.B.; JORGE, A.M.; MOURÃO, R.C.; POLIZEL-NETO, A.; ANDRADE, E.N.; GOMES, H.F.B. Qualidade da carne de cordeiros confinados recebendo diferentes relações de volumoso: concentrado na dieta. Ciência e Tecnologia de Alimentos, v.29, n.2, p.407-411, 2009. http://dx.doi.org/10.1590/S0101-20612009000200028.

PRANDL, O.; FISCHER, A.; SCHMIDHOFER, T.; SINELL, H.Tecnologia e higiene de la carne. Zaragoza: Ed Acribia, 1994.

SILVA, N. Manual de métodos de análise microbiológica de alimentos. São Paulo: Livraria Varela,1997.

SIMÕES, J. A.; RICARDO, R. Avaliação da cor da carne tomando como referência o músculo rectus abdominis, em carcaças de cordeiros leves. Revista Portuguesa de Ciências Veterinárias, v.95, n.535, p.124-127, 2000.

SIQUEIRA, R.S.Manual de microbiologia de alimentos. Brasília: EMBRAPA, 1995. 159 p.

TRUSCOTT, T.G.; HUDSON, J.E.; ANDERSON, S.K. Differences between observers in assessment of meat colour. Proceedings of the Australian Society of Animal Production, v.15, p.762, 1984.

ZEOLA, N.M.B.L.; SILVA SOBRINHO, A.G. Composição química da carne ovina. Revista Nacional da Carne, n.292, p.36-48, 2001. 